Revista Eletrônica do Mestrado em Educação Ambiental

\title{
Diálogos entre a Formação Inicial Docente em Biologia e a temática da Justiça, conflitos e Racismo Ambiental.
}

\author{
Marcelo Aranda Stortti ${ }^{1}$ \\ Celso Pereira Sanchez ${ }^{2}$
}

Resumo: O objetivo deste trabalho foi refletir sobre as construções discursivas de futuros professores de biologia, acerca de articulações entre racismo ambiental, justiça ambiental, educação ambiental e ensino de ciências. Como metodologia desenvolvemos a técnica de grupo focal em 27 alunos da Faculdade de Filosofia, Ciências e Letras de Duque de Caxias (Rio de Janeiro) e a análise de conteúdos. Os resultados encontrados demonstraram pouco conhecimento das temáticas investigadas e uma preponderância de concepções embasadas em uma educação ambiental conservadora. Sobre o tema da justiça e racismo ambiental o grupo demonstrou pouco interesse sobre essas questões e uma confusão teórica. A partir dessa pesquisa podemos supor a necessidade de ampliar o diálogo entre as disciplinas específicas relacionando-as com temas socioambientais mais próximos do cotidiano dos alunos.

Palavras chave: educação ambiental, racismo ambiental, justiça ambiental.

\section{Diálogos entre la Formación Inicial Docente en Biología y la temática de la Justicia, conflictos y Racismo Ambiental.}

Resumem: El objetivo de este trabajo fue reflexionar sobre las construcciones discursivas de futuros profesores de biología, acerca de articulaciones entre racismo ambiental, justicia ambiental, educación ambiental y enseñanza de ciencias. Como metodología desarrollamos la técnica de grupo focal en 27 alumnos de la Facultad de Filosofía, Ciencias y Letras de Duque de Caxias (Río de Janeiro) y el análisis de contenidos. Los resultados encontrados demostraron poco conocimiento de las temáticas investigadas y una preponderancia de concepciones basadas en una educación ambiental conservadora. Sobre el tema de la justicia y el racismo ambiental el grupo demostró poco

\footnotetext{
${ }^{1}$ Departamento de Educação e de Biologia. Desenvolvo projetos e pesquisas desde 1992 em educação ambiental em parceria com movimentos sociais, ONGs e na formação inicial de professores e educadores. Contato: marcelostortti@gmail.com

${ }^{2}$ Pesquisador e professor do programa de pós-graduação em educação da UNIRIO e coordenador do grupo de pesquisa GEASUR Contato: celso.sanchez@hotmail.com

Rev. Eletrônica Mestr. Educ. Ambient. Rio Grande, v. 36, n. 2, p. 60 - 82, mai./ago. 2019.

E-ISSN 1517-1256
} 
interés en estas cuestiones y una confusión teórica. A partir de esta investigación podemos suponer la necesidad de ampliar el diálogo entre las disciplinas específicas relacionándolas con temas socioambientales más cercanos al cotidiano de los alumnos.

Palabras Clave: educación ambiental, racismo ambiental, justicia ambiental.

\title{
Dialogues between the Initial Teacher Training in Biology and the theme of Justice, Conflicts and Environmental Racism.
}

\begin{abstract}
The objective of this work was to reflect on the discursive constructions of future biology teachers, about articulations between environmental racism, environmental justice, environmental education and science education. As a methodology we developed the focus group technique in 27 students from the Faculty of Philosophy, Sciences and Literature of Duque de Caxias (Rio de Janeiro) and content analysis. The results showed little knowledge of the themes investigated and a preponderance of conceptions based on a conservative environmental education. On the subject of justice and environmental racism the group showed little interest in these issues and a theoretical confusion. From this research we can assume the need to broaden the dialogue between the specific disciplines by relating them to socio-environmental themes that are closer to the students' daily lives.
\end{abstract}

Key words: environmental education, environmental racism, environmental justice.

\section{Introdução}

Atualmente a educação ambiental nos espaços escolares no Brasil é desenvolvida de diversas formas pelos professores de diferentes segmentos educacionais. Em 2007 o MEC organizou uma pesquisa com escolas e professores de todo o Brasil determinando como a EA foi desenvolvida naquele período no país. A partir dessa pesquisa, observou-se que a EA era desenvolvida em "3 modalidades: projetos, disciplinas especiais e a inserção da temática ambiental nas disciplinas" (MEC, 2007, p.48).

Além disso, a pesquisa comprovou que o professor que atua na educação básica foi o responsável direto, na maioria dos casos, de forma autônoma, por realizar atividades que dialogam direta ou indiretamente com a educação ambiental. E identificou que a maior inserção desse campo, dentre as diferentes áreas do currículo escolar, está na disciplina específica de ciências naturais. Mesmo com esse papel de destaque das ciências naturais e da ecologia, bem como, da influência do movimento ambientalista, o principal objetivo estabelecido pela maioria das escolas do Brasil para essa temática está relacionada a ideia de: "conscientizar alunos e comunidade para a plena cidadania e sensibilizar para o convívio com a natureza" (MEC, 2007, p.47).

Rev. Eletrônica Mestr. Educ. Ambient. Rio Grande, v. 36, n. 2, p. 60 - 82, mai./ago. 2019. E-ISSN 1517-1256 
Outro fator apontado por essa pesquisa, está na importância de programas que colocam em prática as políticas públicas desse campo e que essas ações na maioria dos casos são desenvolvidas pelo governo federal (MEC, op. cit.).

Essa questão ressalta a importância de ocorrerem mais pesquisas sobre a formação inicial de professores de ciências e biologia abordando diferentes aspectos teóricos e práticas da EA.

Passados mais de 10 anos, como deve estar sendo realizada a educação ambiental pelos professores nos dias de hoje?

Em pesquisa realizada por Menezes (2015) foram analisados os projetos elaborados por professores de escolas públicas de territórios com alto índice de vulnerabilidade ambiental, localizados no Estado do Rio de Janeiro. Esses projetos estão atrelados ao programa das escolas sustentáveis dos Ministérios da Educação e do Meio Ambiente com base na política nacional de educação ambiental e os diversos documentos que servem de fundamentação para o seu desenvolvimento.

Para essa autora o programa governamental das escolas sustentáveis, bem como, os projetos que foram encaminhados das escolas públicas em resposta dessa demanda da política pública, dialogam pouco com as propostas e questões apresentadas por diferentes movimentos sociais em especial o relaciona a tema da justiça ambiental. Esse programa governamental e os seus respectivos projetos escolares não debateram os conflitos socioambientais, contribuindo para não publicização e ou silenciamento dessas questões e dos seus respectivos sujeitos sociais (MENEZES, 2015), na "leitura de mundo" (FREIRE, 1989) e no desvelamento das realidades territoriais.

Menezes (op. cit.) ressalta, ainda, que o Programa Nacional Escolas Sustentáveis aborda o tema das mudanças socioambientais globais, que está na pauta do debate internacional, porém ele se afasta do senso comum mundial relacionado as mudanças de hábitos e debate a redução das possibilidades de manutenção dos ecossistemas, o hiperconsumo de pequenos grupos internacionais e miséria no resto do mundo, gerando conflitos ligados ao consumo de água, seres vivos (alimentos) e energia. A partir dessa forma desigual de acesso aos bens comuns e da exposição aos problemas socioambientais ocorre o aparecimento de injustiças socioambientais, afetando, principalmente, as

Rev. Eletrônica Mestr. Educ. Ambient. Rio Grande, v. 36, n. 2, p. 60 - 82, mai./ago. 2019. E-ISSN 1517-1256 
populações indígenas, quilombolas, campesinos, pequenos agricultores e os grupos sociais em territórios periféricos nas cidades (MENEZES, 2015).

A partir das observações anteriores, podemos destacar que a temática da justiça e do racismo ambiental, não aparece na política governamental, muito menos nos projetos das escolas públicas. Essa ausência de temas relacionados aos contextos históricos que esses sujeitos (professores) estão inseridos pode estar relacionada com a afirmação de Guimarães (2004, p.36)

apesar da difusão crescente da educação ambiental pelo processo educacional, essa ação educativa geralmente se apresenta fragilizada em suas práticas pedagógicas, na medida em que tais práticas não se inserem em processos que gerem transformações significativas da realidade vivenciada.

Depois de refletirmos inicialmente sobre a educação ambiental na prática docente e as políticas públicas implementadas no contexto escolar, faz-se necessário refletir sobre as pesquisas relacionadas a formação inicial dos professores de ciências e biologia e o seu diálogo com os temas da EA, justiça e racismo ambiental. Abaixo destacaremos algumas pesquisas que fazem essa interseção.

Barros e Queiros (2015) fizeram uma pesquisa do tipo Estado da Arte sobre a temática da EA a partir do levantamento de artigos publicados de 2010 a 2014 em periódicos brasileiros da área de ensino, classificados segundo o CNPQ pelo Qualis B1, A2 e A1. Nesse trabalho as autoras identificaram que a maioria das pesquisas se limitou a determinar as concepções/percepções de professores em processo inicial ou continuado de formação sobre EA e que faltou debates da dimensão política e socioambiental nos cursos de formação inicial e continuada, bem como, nos currículos desses cursos.

$\mathrm{Na}$ pesquisa descrita anteriormente, foram abordadas algumas categorias, porém só apresentaremos aquela relacionada com as questões socioambientais. $\mathrm{Na}$ análise de Barros e Queiros (op. cit.) os artigos investigados evidenciaram os problemas socioambientais e destacaram a importância de se debater sobre essa questão. Além disso, as autoras afirmam que $51,42 \%$ das pesquisas analisadas se dedicam a identificar as concepções/percepções que docentes e licenciandos têm sobre conceitos ambientais, destacando que esse grupo social demonstrou ter visões antropocêntricas, simplistas, naturalistas, utilitaristas.

Rev. Eletrônica Mestr. Educ. Ambient. Rio Grande, v. 36, n. 2, p. 60 - 82, mai./ago. 2019. E-ISSN 1517-1256 
Outra questão identificada nesse estudo está relacionada a propostas de criação de cursos ou programas de formação continuada, para melhorar os conceitos desses profissionais, porém para essas autoras esse modelo de formação deve ser proposto embasado no categoria intelectual crítico transformador, pois permitiria desenvolver um determinado tipo de educação ambiental que contribua para a emancipação (BARROS; QUEIROS, op. cit.). Como podemos observar o tema da justiça e racismo ambiental não apareceu na análise anteriormente apresentada.

Aprofundando o levantamento de pesquisas que dialoguem com a temática proposta nessa pesquisa, a investigação de Guimarães e Alves (2012) analisou como a formação de professores em EA tem sido estudada nas publicações do Grupo de Trabalho (GT) 22 nas reuniões da Associação Nacional de Pós-Graduação e Pesquisa em Educação (ANPEd) entre os anos de 2009, 2010 e 2011. Nessa pesquisa os autores estabeleceram as categorias: Críticas ao reducionismo da EA; EA crítica como possibilidade de superação da EA vigente; Experiências de EA mediadas pela pesquisa-ação; e Desafios na operacionalização da legislação que institui a EA (GUIMARÃES; ALVES, op. cit., p. 53).

A organização em categorias permitiu a visualização de como a temática "formação de professores/educadores em EA" tem sido desenvolvida pelos pesquisadores, ou seja, quais são as principais preocupações destacadas pelos autores que têm estudado o assunto nos últimos anos. Concluiu-se que essas temáticas refletem o quanto os pesquisadores que se ocupam da formação docente em EA estão preocupados em denunciar a situação atual do educador ambiental. percebemos a necessidade de aumentar as discussões acerca da formação de professores para a educação ambiental, nos seguintes aspectos: a reflexão crítica, a autonomia, valorização da diversidade, interdisciplinaridade, os aspectos das relações ciência, tecnologia sociedade e ambiente (CTSA). Tais aspectos têm por finalidade formar professores e cidadãos que saibam lidar com os problemas socioambientais.

Já Souza, Costa e Bomfim (2015) após investigarem os módulos da disciplina Educação Ambiental (EA) do Curso de Licenciatura em Ciências Biológicas do Centro de Educação Superior a Distância do Rio de Janeiro, com o intuito de refletir sobre a formação desses potenciais educadores ambientais. Essa investigação permitiu descrever os conteúdos da disciplina, verificaram que a mesma traz uma abordagem crítica das

Rev. Eletrônica Mestr. Educ. Ambient. Rio Grande, v. 36, n. 2, p. 60 - 82, mai./ago. 2019. E-ISSN 1517-1256 
questões ambientais, perpassando por temas voltados para mudança social, de forma interdisciplinar e questionadora do modelo societário atual. Um resultado surpreendente à disciplina, mas que, ao mesmo tempo, contribuiu para apontar as contradições sobre o próprio modelo de curso.

Para Guimarães e Alves (2012) as pesquisas, por eles realizadas, permitem observar uma concentração de opiniões desse grupo social baseadas em ideias superficiais e difusas acerca do ambiente e da EA. Além disso, podemos observar que essas ideias promovem reflexos na prática docente, pois segundo uma pesquisa nessa área realizada por TozoniReis, Teixeira e Maia (2011, p. 5) "fica reduzida a busca empírica de informações, materiais didáticos, recursos humanos e condições de infraestrutura da escola, secundarizando a dimensão intelectual mais sofisticada da práxis educativa escolar".

Na pesquisa realizada por Barros e Queiros (2015) foi identificado a existência de poucos estudos sobre a formação de professores em diálogo com a temática ambiental, principalmente quando se analisa os modelos formativos, destacando a necessidade de se fazer pesquisas que relacionem a formação de professores e educação ambiental e aprofundem uma reflexão sobre as fundamentações teóricas relacionando-as aos modelos formativos de professores (BARROS; QUEIROS, op. cit.).

E finalizando essa revisão da literatura sem esgotar o tema, apresento os resultados da pesquisa de Tozoni-Reis e Campos (2015, p.107) que reforçam as fragilidades do processo de inserção da EA na escola destacando diversos pontos, tais como: políticas públicas de educação ambiental escolar, a presença de atores externos à escola em seu cotidiano, a organização da escola, a organização dos currículos escolares, as condições de trabalho dos professores, o problema da formação dos professores.

Essas autoras ressaltaram que uma dessas fragilidades, também pode ser um elemento para melhorar o estado atual da inserção da EA na vida escolar. Para tal, elas analisaram alguns pontos interessantes com a "fraca" formação teórica e prática, bem como, a desarticulação entre elas, dos futuros professores egressos de cursos de licenciatura e a desvalorização e proletarização do fazer docente. Elas reforçam a necessidade de mudarmos a lógica do processo formativo dos estudantes universitários de uma racionalidade prática em diálogo com atitudes e competências, isto é, "know-how" de visualizar e solucionar um tema ou problema.

Rev. Eletrônica Mestr. Educ. Ambient. Rio Grande, v. 36, n. 2, p. 60 - 82, mai./ago. 2019. E-ISSN 1517-1256 
Essa racionalidade almeja que o futuro educador tenha esses princípios incorporados no seu discurso e na sua prática, para que as mesmas sejam difundidas entre os alunos que se formam no ensino médio e porque elas são cobradas na prova do Exame Nacional do Ensino Médio (ENEM). E para contrapor esse processo formativo vigente essas pesquisadoras sugerem que os futuros professores sejam formados em um ambiente que valoriza o conhecimento científico e cultural da humanidade de forma crítica e transformadora (TOZONI-REIS; CAMPOS, 2015).

Como podemos observar a área apresenta uma boa produção acadêmica, porém concentrada em subáreas específicas, sendo necessário ampliar esse escopo para outras questões também pertinentes a esse tema gerando uma nova agenda de investigação.

O objetivo deste trabalho foi refletir sobre as construções discursivas de futuros professores de ciências e biologia de uma universidade particular localizada em Duque de Caxias (Rio de Janeiro), acerca de articulações entre racismo ambiental, justiça ambiental, educação ambiental (EA) e ensino de biologia.

\section{Referencial teórico}

Nessa investigação buscamos dialogar com os temas anteriormente explicitados com o quadro teórico do campo da justiça ambiental, do racismo ambiental e da decolonialidade.

No campo da Justiça Ambiental o termo foi estabelecido para denominar um quadro de vida futuro no qual essa dimensão ambiental da injustiça social venha a ser superada. Essa noção tem sido utilizada, sobretudo, para construir uma nova perspectiva a integrar as lutas ambientais e sociais. (ACSELRAD; MELLO; BEZERRA, 2009, p. 20)

A partir disso, pensamos que o diálogo entre o campo da educação ambiental e a justiça ambiental pode ser preponderante para desvelar condições desiguais nas disputas econômicas, sociais e políticas, além de dar visibilidade as lutas socioambientais e os enfrentamentos que desabrocham dos conflitos ambientais (MENEZES, 2015).

Complementando esse pensamento buscamos na teoria do giro decolonial (QUIJANO, 2000; MIGNOLO, 2008), que estabelece como referencial conceitual que o conhecimento não é elaborado de uma posição neutra, senão de ideias privadas dos sujeitos

Rev. Eletrônica Mestr. Educ. Ambient. Rio Grande, v. 36, n. 2, p. 60 - 82, mai./ago. 2019. E-ISSN 1517-1256 
sociais estabelecido por uma padronazem elaborada através da construção cultural do sistema-mundo capitalista moderno/colonial.

Aprofundando essas ideias, Pacheco e Faustino (2013) observaram que para se pensar e conversar sobre racismo ambiental, faz-se necessário compreender a questão racial e o etnocentrismo como problemas importantes, pois se inserem diferentes grupos sociais diretamente nessa questão.

De acordo com essas autoras esse conceito está atrelado ao processo de discriminação racial nas políticas ambientais, bem como, no aplicação das resoluções dos conselhos federais, estaduais e municipais e da legislação e na escolha territorial prédeterminada para industriais e outras atividades econômicas com grande risco de problemas e ou crimes socioambiental em localidades com populações pretas e pardas (PACHECO, FAUSTINO, 2013), como estudados recentemente no caso do rompimento da Barragem de Mariana ocasionando um crime socioambiental fatal para várias pessoas.

Tal reconhecimento permite caracterizar a problemática racial e étnica tanto como fator de produção das injustiças que tais grupos enfrentam quanto como elemento da constituição dos poderes políticos, econômicos e culturais dominantes, que controlam a implementação e o funcionamento das atividades econômicas geradoras desses conflitos (PACHECO; FAUSTINO, 2013, p. 74).

Logo podemos pensar que está ocorrendo um "branqueamento" (FANON, 1974) ambiental, interligado aos casos de racismo ambiental não descritos no cotidiano escolar, pois coincidentemente esses territórios onde as escolas públicas estão inseridas, apresentam populações onde a maioria são negros e pardos.

De acordo com Fanon (op. cit.) esse processo de branqueamento, isto é, promover a despigmentacão da pele e do pensamento para assimilar a supremacia do asséptico, puro, luminoso e inmaculado do "branco".

Esse autor aprofunda a sua análise afirmando da importância de estudar as relações entre o racismo e a cultura, devido ao seu caráter de ação recíproca. Para ele o racismo é um elemento da cultura dos povos, sendo constantemente adaptado, se renovando, em coevolução com a cultural das elites internacionais e locais, sendo naturalizado pelas camadas populares.

Rev. Eletrônica Mestr. Educ. Ambient. Rio Grande, v. 36, n. 2, p. 60 - 82, mai./ago. 2019. E-ISSN 1517-1256 
As reflexões de Frantz Fanon dialogam diretamente com os processos de silenciamentos dos diálogos entre os conteúdos biológicos e raciais nos espaços escolares e nas instâncias de formação de professores. Isso deve estar atrelado a diversos fatores, porém podemos destacar como principal fator os argumentos biológicos falaciosos que alguns grupos internacionais, como a Organização Mundial da Saúde (OMS) criam para tornar o racismo não apenas individual, mais intrínseco a cultura de uma sociedade. A OMS financiou pesquisas para criarem narrativas como a "lobotomia fisiológica do negro da África" (FANON, op. cit., p. 36) que se tornam "verdades científicas" inquestionáveis, sendo massificadas nas camadas populares pelos editoriais de diferentes mídias das elites locais.

Essa questão está relacionada ao processo da colonialidade em suas diferentes maneiras de existir tais como: poder, saber e do ser (QUIJANO, 2001), que entra em conflito com a diversidade de cores das peles, dos seus saberes e fazeres, sendo necessário "pintar" de branco e ou "matizalo" na epiderme e nas mentalidades para uniformizar e constituir o padrão eurocêntrico (ACHINTE, 2009).

\section{Metodologia}

Iniciamos essa pesquisa com uma revisão de literatura em revistas científicas, nos anais de congressos do campo e nos bancos de Teses da CAPES, do projeto EArte e na Biblioteca Digital de Teses e Dissertações (BDTD) relacionadas ao tema da educação ambiental e a formação inicial de professores disponíveis na internet.

Depois de definirmos o nosso objeto de estudo e construirmos um objetivo para essa pesquisa surgiu a necessidade de escolhermos quais seriam os sujeitos da pesquisa e como iríamos investiga-los. Nessa busca, escolhemos uma turma de 27 alunos do penúltimo período de uma Faculdade privada localizada no município de Duque de Caxias, pois essa instituição estava totalmente dedicada a formação inicial e complementar de professores de diferentes áreas e se localizada na Baixada Fluminense do Rio de Janeiro, uma região com grandes desigualdades sociais e próxima de grandes empreendimentos industriais potencialmente poluidores.

Rev. Eletrônica Mestr. Educ. Ambient. Rio Grande, v. 36, n. 2, p. 60 - 82, mai./ago. 2019. E-ISSN 1517-1256 
Posteriormente analisamos o Projeto Pedagógico do Curso (PPC), com o objetivo de entender como é proposto o trabalho com o tema da EA e da justiça e racismo ambiental ao longo do processo de formação teórica e prática dos futuros professores do curso de Ciências Biológicas da Faculdade anteriormente citada

Logo em seguida foi realizada uma reunião com a direção da Faculdade, quando foi solicitado a realização da pesquisa. Após a aprovação da direção, foi realizado uma conversa com os alunos do curso convidando-os para participar da pesquisa.

As pesquisas qualitativas, podem ser caracterizadas por sua diversidade metodológica (ALVES-MAZZOTTI; GEWANDSZNAJDER, 1998), nessa pesquisa fizemos a opção de usar como instrumento para a coleta de dados o procedimento chamado de grupo focal.

De acordo com Gondim (2003) o grupo focal é uma técnica derivada das entrevistas em grupo, permitindo o levantamento de dados por meio de interações entre os participantes do grupo. Trad (2009) complementa a caracterização dessa técnica afirmando ser uma forma de entrevista grupal, relacionada com a interação comunicacional dos participantes. O seu objetivo central pode estar relacionado a agrupar detalhadamente informações sobre determinada temática (sugerido pelo responsável por essa atividade com um grupo específico), permitindo levantar dados que possam colaborar com o entendimento das percepções, crenças, atitudes sobre um tema, produto ou serviços (TRAD, op. cit.).

Para iniciarmos a coleta de dados, foi realizada a leitura do termo de consentimento e pedido a autorização para filmar a atividade, que foi realizada por meio de uma filmadora (modelo Sony handycam PJ6). Logo em seguida, iniciou-se o procedimento com uma breve apresentação de cada participante e sua experiência de vida. Para estimular o debate entre os participantes, foi perguntado sobre o que eles achavam sobre a grande presença de empresas de grande porte naquela região. Após algumas falas dos participantes, foi perguntado se aquelas empresas traziam alguma contribuição ou problema para a região. Depois foi questionado se eles gostariam de ser professores e que temas eles gostariam de ensinar. E depois foi perguntado sobre o que eles achavam da educação ambiental e como eles iriam trabalhar esse tema na escola. E no final o que eles entendiam sobre justiça e racismo ambiental. O grupo focal teve duração total de uma hora e dez minutos.

Rev. Eletrônica Mestr. Educ. Ambient. Rio Grande, v. 36, n. 2, p. 60 - 82, mai./ago. 2019. E-ISSN 1517-1256 
Após a realização do grupo focal, iniciou a análise de dados, destacando as falas de acordo com o grau de similaridade, discordância, bem como palavras chaves que emergiram durante o procedimento grupal, com base na análise de conteúdos de Laurence Bardin (1973).

\section{Resultados e Discussões}

Após a análise do PPC do curso de Ciências Biológica, fica claro a ausência de questões relacionadas ao entorno da instituição, dos alunos e das condições sócio-históricas e políticas da Baixada Fluminense, região que foi caracterizada na literatura como uma zona de sacrifício socioambiental (ACSELRAD, 2004), pois nessa região a exposição a produtos e resíduos do processo produtivo das empresas que estão nesse território promovem processos de adoecimento e morte na população, principalmente daqueles que residem próximo das atividades industriais.

O curso, apresenta uma disciplina específica sobre educação ambiental cuja ementa contempla as diferentes dimensões da educação ambiental, menos as questões ligadas aos conflitos, injustiças e o racismo ambiental. Essa disciplina apresenta carga horária pequena gerando um tempo muito curto para trabalhar esses conteúdos em profundidade.

A análise da gravação do grupo focal permitiu observar e identificar várias questões, tais como: uma visão conservadora da EA e um confusão teórica muito grande dos alunos sobre os temas analisados. Apenas dois alunos falaram sobre a questão crítica da EA, porém não conseguiram aprofundar essa temática, nem tão pouco relaciona-la com os temas da justiça e racismo ambiental.

Provavelmente alguns autores (GUIMARÃES, 2004; DIAS, 2000) falariam da falta ou do processo inicial de construção de uma consciência ecológica nesse grupo social. Porém, sabemos que esse processo é interno e que não depende de comportamentos ecologicamente certos ou transferência de conhecimentos que levam essa mesma adjetivação para resolvermos os problemas ambientais.

A partir dessa reflexão, podemos chamar atenção para o processo de "colonização" inicialmente eurocentrada (DUSSEL, 1993) e depois na sua face imperialista (BORON, 2000) da cultura, economia, política, bem como, dos corpos, do seu imaginário, dos

Rev. Eletrônica Mestr. Educ. Ambient. Rio Grande, v. 36, n. 2, p. 60 - 82, mai./ago. 2019. E-ISSN 1517-1256 
saberes e dos fazeres promovendo o "encobrimento do outro" (DUSSEL, op. cit., p.58), isto é, o apagamento do mundo do outro com todos os seus elementos míticos e a construção do imaginário do valor negativo, com adjetivos depreciativos para a época, como "pagão, satânico e intrinsecamente perverso" (DUSSEL, op. cit., p.60).

Nos dias atuais esse processo colonizador opressor se constitui através do projeto Hegemônico educativo da Organização das Nações Unidas (ONU) e das suas diversas agências internacionais e o seu projeto de esvaziamento do conceito e do campo da EA e a construção ideológica de um modelo de desenvolvimento adjetivado por sustentável (UCHOA, 2015).

Esse modelo de desenvolvimento propagado pela ONU e as suas agências (UNESCO, PNUMA, FAO, ONU-Habitat, FMI, Banco Mundial etc) incute na educação a obrigação de construir a grande narrativa ideológica de "dominação capitalista" (ACCIOLY, 2015, p.71). Esse modelo de desenvolvimento apresenta uma heterogeneidade na sua cadência, resultando em um processo autóctone nos países periféricos, como o Brasil, promovendo uma desigualdade gigantesca entre os seus cidadãos, além de impelir aspectos "modernos", suscitando "encobrimentos" e adaptações relacionadas as condições socioculturais desses regiões. Essa junção de inovações tecnológicas e adequações a realidade de cada país constitui a forma combinada que o capitalismo imperialista se impõe ao mundo.

Outra questão levantada durante a coleta de dados, está relacionado ao interesse, desse grupo, pelo tema da saúde. Os sujeitos dessa pesquisa conseguem relacionar os problemas respiratórios da população com a poluição do ar provocada pelos resíduos industriais. Um aluno chegou a dizer que as empresas queimam os produtos tóxicos na parte da noite, aumentando as chamas das chaminés, e quando são perguntadas dizem que a poluição do ar está relacionada ao grande volume de caminhões e automóveis que circulam naquele horário, sendo corroborado por todo o grupo, porém esses alunos não conseguiram relacionar essa problemática e a sua importância para o contexto da sala de aula.

Como podemos observar mesmo com um processo educativo hegemônico, associado a burguesia local (empresas, sistema "S", movimentos ligados ao patronato como o "todos pela educação", fundações etc) que impõem a sua agenda "verde" Rev. Eletrônica Mestr. Educ. Ambient. Rio Grande, v. 36, n. 2, p. 60 - 82, mai./ago. 2019. E-ISSN 1517-1256 
insustentável homogeneizando. Esse grupo social buscou re-existir em seus territórios, construindo outras formas de refletir sobre a temática socioambiental, associando as questões das injustiças ambientais, principalmente as relacionadas a exposição aos poluentes dos processos produtivos da cadeia do petróleo.

Como afirmava Paulo Freire, desnudar o "veu" das tramas em que a concretude da vida se dá, isto é, entender de forma profunda a lógica da opressão, não é suficiente para permitir que esses sujeitos sociais ganhem a alforria das algemas do capitalismo. Esse processo de autodescobrimento é um passo muito importante para desbancar o "rolo compressor" do imperialismo globalizante, porém faz-se necessário o "engajamento na luta política pela transformação das condições concretas em que se dá a opressão" (FREIRE, 1997, p. 16). Esses futuros professores através desse olhar relacional saúde-poluição empresarial buscam pensar em ações pedagógicas que dialogam com o pensamento histórico-crítico e libertário (LEHER, 2015).

Esse processo de transformação da realidade, já foi tema central da educação ambiental após a Conferência Intergovernamental sobre Educação Ambiental que ocorreu em Tbilisi (Georgia) que a determinou como:

O elemento essencial de uma educação global e permanente, orientada para a solução de problemas e a preparação para a participação ativa, deve ajudar a canalizar os sistemas educacionais no sentido de maior adequação, maior realismo e maior interpenetração com os demais. ambiente natural e social, com vista a facilitar o bem-estar das comunidades humanas (UNESCO, 1980, p.2).

Porém a proposta dessa agência da ONU, como falamos anteriormente tem interesses em incentivar que as inovações criadas pelos países mais desenvolvidos, baseadas na ciência e tecnologia que eles produzem e vedem sejam compradas e aplicadas pelos outros países como podemos observar na afirmação dessa instituição transnacional:

a educação não pode resolver todos os problemas ambientais, que são imputáveis a uma série de fatores físicos, biológicos e ecológicos, econômicos, sociais e culturais, mas que, com a ajuda da ciência e da tecnologia, podem contribuir para a formulação de outras soluções possíveis, baseadas na equidade e na solidariedade. (UNESCO, 1980, p.2).

Rev. Eletrônica Mestr. Educ. Ambient. Rio Grande, v. 36, n. 2, p. 60 - 82, mai./ago. 2019.

E-ISSN 1517-1256 
Como podemos observar no fragmento acima, essa agência propõe esvaziar a dimensão política e as contradições internas de cada país, bem como, a possibilidade da luta coletiva de oprimidas e oprimidos para a transformação das suas condições de vida e de seu próprio modo de produção.

Paulo Freire reforça essa ideia afirmando que o

(...) discurso neoliberal e a sua prática educativa no Brasil e fora dele, a recusa sistemática do sonho e da utopia, o que sacrifica necessariamente a esperança. A propalada morte do sonho e da utopia, que ameaça a vida da esperança, termina por despolitizar a prática educativa, ferindo a própria natureza humana. (...) nenhuma realidade é assim porque assim tem de ser. Está sendo assim porque interesses fortes de quem tem poder a fazem assim (FREIRE, 2000, p. 56).

$\mathrm{Na}$ concepção de Layrargues (2001) as propostas de Tibilisi demonstram que o colapso socioambiental está relacionado projeto sociocultural da geopolítica fabril, principalmente as indústrias que os países "desenvolvidos" não querem ter em seus territórios, devido aos problemas socioambientais que as mesmas causam. Esse tipo de modelo planetário está associado ao modelo regulatório de mercado, gerando uma forma de ver o mundo de um único modo e a sua função ou forma de ser apropriar-se da natureza. Segundo esse autor essa ideia supera a forma de ver esse campo (EA) e os problemas que surgem desse processo econômico desenvolvimentista para além da: questão da explosão demográfica, agricultura moderna, e a crescente urbanização e industrialização, como se tais fenômenos estivessem dissociados da visão de mundo instrumental da sociedade na qual foram originados (LAYRARGUES, op. cit., p. 132).

Esse pesquisador afirma que esse documento, também, contribui para uma prática educativa mais contextualizada e menos inocente e elementar, pois supera a ideia desse campo relacionado exclusivamente a princípios da disciplina ecologia e dos problemas que todos os seres humanos causam de forma igual a natureza. Essa proposta permite ao educador construir a sua prática pedagógica com base nos problemas que afetam o grupo social que estudam na escola que ele trabalha. Porém, na análise dele dois tipos de formas distintas podem surgir no trabalho docente relacionado a esse campo: tema-gerador de onde se irradia uma concepção pedagógica comprometida com a compreensão e

Rev. Eletrônica Mestr. Educ. Ambient. Rio Grande, v. 36, n. 2, p. 60 - 82, mai./ago. 2019. E-ISSN 1517-1256 
transformação da realidade; ou como uma atividade-fim que visa unicamente a resolução pontual daquele problema ambiental abordado (LAYRARGUES, op. cit., p. 132).

Como podemos observar a atividade-fim não acrescentará quase nada aos futuros professores e aos educandos da escola básica, porém o tema-gerador, como proposto por Freire (1987, p.50) é algo a que chegamos através, não só da própria experiencia existencial, mas também de uma reflexão crítica sobre as relações homens[mulheres]mundo e homens[mulheres]-homens[mulheres], implícitas nas primeiras (grifo nosso).

Paulo Freire, reforça essa ideia de pesquisa temática, apontando a necessidade de entender de forma crítica a totalidade das coisas em seu mundo, percebendo fragmentadamente e consequentemente tendo dificuldade de identificar a inter-relação da vida em sua totalidade. Na concepção desse autor, pesquisar um tema gerador, propicia o re-pensar da concretude da vida material e o seu agir sobre a mesma, sendo essa pensaração-reflexão, chamado de práxis (FREIRE, op. cit., p.56).

Nesse processo de desvelamento temático, identificamos, como apresentado na breve revisão bibliográfica, que os temas das in-justiças e dos conflitos ambientais em diálogo com a EA, tem chamado a atenção de pesquisadores e movimentos sociais, porém o tema do racismo, especialmente aquele atrelado a sua dimensão ambiental, apresenta pouquíssimas investigações.

Nessa pesquisa esse tema, foi o que promoveu debate mais intenso, porém pouco relacionado ao conceito em si. Esse grupo de alunos chamou atenção para a importância do tema do racismo, porém falaram que esse tema é muito "falado" porém nada muda e que na escola já tem muito assunto para se falar, e ainda teriam que falar sobre isso?

Dialogando com Selene Herculano esse tipo de racismo está associado às injustiças sociais e ambientais que recaem de forma desproporcional sobre etnias vulnerabilizadas (HERCULANO, 2008, p. 16). Porém, temos observado que ele vai além de grupos étnicos, pois comunidades que em sua maioria são negras das periferias de centros urbanos ou pequenos aglomerados populacionais de cidades de médio porte, também tem sofrido das desigualdades e injustiças socioambientais de grandes corporações, instalações industriais, usinas hidrelétricas, do agronegócio, estradas, ferrovias etc, que expulsam de suas residências, desestruturando seus laços afetivos, familiares, condições produtivas e de trabalho.

Rev. Eletrônica Mestr. Educ. Ambient. Rio Grande, v. 36, n. 2, p. 60 - 82, mai./ago. 2019. E-ISSN 1517-1256 
Nesse segundo caso, estamos falando da experiência de vida da maioria desses alunos que residem próximo de algum tipo de empreendimento econômico que causam problemas socioambientais de diversas ordens, porém os impactos que eles mais perceberam foi na área da saúde devido principalmente pela poluição do ar.

Depois um aluno chamou atenção para as políticas de cotas raciais criticando os programas existentes e dizendo que só se cria a facilidade para os alunos do ensino médio, por isso eles estão estudando pouco. Essa fala em particular gerou grande debate no grupo fugindo do foco do tema ambiental.

Esse debate acalorado, vai além de apenas uma forma dos alunos demonstrarem suas ideias sobre um tema, pois como afirma Queiroz; Miranda (2017, p.5) alguns desses discursos em relação ao tema das políticas de ação afirmativa de recorte racial auxiliam a construção da identidade branca nos espaços universitários, contribuindo para o desvelamento das suas formas de ser e se manifestar no mundo.

Essa ideia pode ser melhor esclarecida com a afirmação de Bento (2002, p.5) "a branquitude é um lugar de privilégio racial, econômico e político, no qual a racialidade, não nomeada como tal, carregada de valores, de experiências, de identificações afetivas, acaba por definir a sociedade".

Esse processo de constituição do encobrimento do outro (DUSSEL,1993), dialoga com a temática da branquitude, pois conforme a definição anterior, podemos supor que os alunos, sujeitos dessa pesquisa, não se preocupem em lutar por seus direitos e oportunidades, porque não se reconhecem como negros, como afirmava Fanon (1974) a negação da cor da própria pele, buscando fugir das ideias negativas associadas aos que não são de cor branca, e nem se acham totalmente "brancos" para ter esse mesmo privilégio racial.

Essa análise pode ser reforçada, pela nossa observação acerca do desconhecimento por parte desse grupo da lei federal $n^{\circ} 11.645$ de 2008 que alterou a lei federal $n^{\circ} 10.639$ de 2003 que tornou obrigatório o estudo da história e cultura afro-brasileira e indígena nos estabelecimentos de ensino fundamental e médio (GUSMÃO, 2013) e de qualquer possibilidade de dialogo desse instrumento legal com o tema do racismo ambiental. Logo podemos pensar, dialogando com Fanon (op. cit., p. 83) a prática racista se encontra inscrita na estrutura social, econômica, histórica e cultural das sociedades ocidentais, isto é,

Rev. Eletrônica Mestr. Educ. Ambient. Rio Grande, v. 36, n. 2, p. 60 - 82, mai./ago. 2019. E-ISSN 1517-1256 
na nossa sociedade o que está ocorrendo não é uma manifestação de um sujeito, mais sim um projeto hegemônico cultural de dominação, denominado de racismo estrutural.

Essa prática racista está relacionada ao processo de constituição da América, se tornando o seu modelo de dominação que posteriormente foi implementado no resto do mundo. Esse modelo de poder centrado na colonialidade do poder, saber e do ser. Esse processo colonial se constituiu através de uma proposta de dominação que controla a compra e venda da força de trabalho, de seus recursos e de seus produtos, em torno do capital e do mercado mundial (QUIJANO, 2000, 117).

Retomando as questões teóricas anteriormente apresentadas e entremeadas com os dados empíricos, podemos pensar que o conceito de justiça ambiental, que está interligado a um tipo de modelo de crescimento econômico que provoca prejuízos ao meio ambiente e a população do entorno (ALIER, 2007), seja mais difícil de ser trabalhado devido aos processos de despolitização que ocorrem nas formações para professores, em detrimento da hegemonia da tecnificação do fazer pedagógico dos futuros professores.

Outra questão que pode auxiliar nas reflexões anteriores é o processo de hibridização cultural que se instalam em grupos sociais complexos, permitindo a construção de identidades fluidas em constante transformação (CANDAU, 2009), logo podemos pensar que os alunos universitários ainda têm dificuldades de sair do lugar de alunos de escolas públicas dessas zonas de sacrifícios para pensar em desvelar profundamente a sua realidade através de processos educativos.

Como podemos observar a dificuldade de entendimento da justiça ambiental pode também estar associada a dificuldade dos alunos se afastarem de uma visão de justiça como direito individual e privilégio de determinados sujeitos coletivos e não identificarem que nessas regiões onde os grandes complexos industriais estão instalados, foram escolhidas esses territórios justamente devido a dificuldades de recursos monetários de sua população, bem como, da pequena influência política para impedir a instalação dessas empresas.

Essas ideias podem estar associadas ao processo de Colonialidade do Poder que se organizam pelas relações de colonialidade nas esferas econômicas, culturais e políticas que não se encerraram com a libertação administrativa de nosso país, mais que são acentuadas

Rev. Eletrônica Mestr. Educ. Ambient. Rio Grande, v. 36, n. 2, p. 60 - 82, mai./ago. 2019. E-ISSN 1517-1256 
pelas estruturas e seus processos de dominação cultural implementados pelo sistemamundo capitalista moderno/colonial (QUIJANO, 2000).

\section{Considerações Finais}

Nessa pesquisa buscou-se identificar as ideias dos futuros professores de biologia com temas da atualidade, que devido as características dos territórios em questão, bem como, das condições de desigualdades sociais faz-se necessários dialogar com novas temáticas aproximando o cotidiano dos alunos, da escola e dos professores. Essa aproximação permite que os futuros professores contextualizem mais os conteúdos abordados no espaço escolar, trazendo os alunos para um processo de desvelamento das realidades socioambientais desiguais e permitindo um diálogo e uma publicização das injustiças e dos casos de racismo ambiental para outras pessoas buscando o enfrentamento destas questões que provavelmente afastam os alunos das salas de aulas, por diferentes motivos, porém direta ou indiretamente relacionados com essas temáticas. Além disso, permite um processo de EA crítica mais direcionado a transformação da realidade dada dos alunos desses territórios.

Pensando, no aprofundamento dessa temática e na ampliação das parcerias entre diferentes movimentos sociais e as escolas, se faz necessária uma ampliação dos diálogos entre as políticas públicas de educação ambiental com a temática étnico racial conforme apontada na Lei Federal 10639/2003, que dispõe da obrigatoriedade da inserção do tema afro-brasileira no currículo escolar (MENEZES, 2015).

A partir dos diálogos anteriores, defende-se a inserção das dimensões pedagógicas das injustiças, conflitos e do racismo ambiental em diálogo com a lei federal no 11.645 de 2008 nas práticas de educação ambiental críticas no contexto das escolas públicas, principalmente em territórios de zonas de sacrifício (MENEZES,2015). Além disso, essa pesquisa deseja contribuir com o debate do campo e aspirando a construção de uma educação antiautoritária e antirracista.

\section{Referências}

Rev. Eletrônica Mestr. Educ. Ambient. Rio Grande, v. 36, n. 2, p. 60 - 82, mai./ago. 2019. E-ISSN 1517-1256 
ACHINTE, Adolfo Albán. Artistas indígenas y afrocolombianas: Entre las memorias y cosmovisiones estéticas de la resistencia. In MIGNOLO, W; PALERMO, Z.. Arte y estética en la encrucijada descolonial. Ediciones del Signo, 2009.

ACSELRAD, H.. As práticas espaciais e o campo dos conflitos ambientais. In: Conflitos Ambientais no Brasil. H. ACSELRAD (org). Rio de Janeiro: Relume Dumará; F. Heinrich Böll, 2004.

ACSELRAD, H. Ambientalização das lutas sociais - o caso do movimento por justiça social. Estudos Avançados. 24 (68), 2010. Disponível em: http://www.scielo.br/scielo.php?pid=S010340142010000100010\&script=sci_arttext. Acesso em 10 de janeiro de 2014.

ACSELRAD, H.; MELLO, C.C.A; BEZERRA, G.N.. O que é Justiça Ambiental. Rio de Janeiro: Garamond, 2009.

ACCIOLY, I.. Ideologia do desenvolvimento e do consumo sustentável na educação ambiental: uma análise das políticas publicas na Década da Educação para o Desenvolvimento Sustentável. In In LOUREIRO, C.F.B.; LAMOSA, R. A. C.. Educação ambiental: um balanço crítico da Década da Educação para o Desenvolvimento Sustentável. Rio de Janeiro: Quarter: CNPQ, p. 68 - 104, 2015.

BARROS, T. G. E.; QUEIROS, W. P.. Estado da Arte sobre as pesquisas de formação de professores na Educação Ambiental. X Encontro Nacional de Pesquisa em Educação em Ciências - X ENPEC Águas de Lindóia, SP - 24 a 27 de Novembro de 2015. Disponível em: http://www.abrapecnet.org.br/enpec/X-enpec/anais2015/resumos/R1991-1.PDF. Acesso em:10/06/16.

BENTO, M. A. S.. Pactos narcísicos no racismo: branquitude e poder nas organizações empresariais e no poder público. 2002. Tese (doutorado em psicologia). Universidade de São Paulo, São Paulo, 2002.

BERNAL, A. B.. A construção do Programa Estadual de Educação Ambiental do Rio de Janeiro: disputas pela agenda pública em tempos de hegemonia neoliberal. Rio de Janeiro: UFRJ, 2012.

BORON, A. A.. America Latina en la Geopolitica del Imperialismo. Argentina: LUXEMBURG, 2012.

CANDAU, V. M.. Educação Intercultural na América Latina: entre concepções, tensões e propostas. São Paulo: Editora São Paulo. 2009.

CAPELLA, V. B.. El movimiento por la justicia ambiental: entre el ecologismo y los derechos humanos. In: Anuario de filosofía del derecho XIII. Universitat de València.1996.

Rev. Eletrônica Mestr. Educ. Ambient. Rio Grande, v. 36, n. 2, p. 60 - 82, mai./ago. 2019. E-ISSN 1517-1256 
CONSENZA, A.; MARTINS, I.. Possibilidades e limites de uma formação para justiça ambiental na escola. In: Caderno de resumos. III Seminário de Justiça Ambiental, Igualdade Racial e Educação. Editora Unigranrio, Rio de Janeiro, 2013.

DIAS, G. F.. Educação Ambiental: princípios e práticas. São Paulo: Gaia. 2000.

DUSSEL, E.. 1492 o encobrimento do outro: a origem do mito da modernidade: Conferências de Frankfurt. Petrópolis, RJ: Vozes. 1993.

FANON, F.. Em Defesa da Revolução Africana. São Paulo. Terceiro Mundo.1974.

FREIRE, P.. A importância do ato de ler: em três artigos que se completam. São Paulo: Autores Associados: Cortez, 1989.

FREIRE, P. Pedagogia do Oprimido. Rio de Janeiro: Paz e Terra, 1987.

FREIRE, P. Pedagogia da Esperança: um reencontro com a Pedagogia do Oprimido. Rio de Janeiro: Paz e Terra, 1997.

FREIRE, P. Pedagogia da Indignação: cartas pedagógicas e outros escritos. São Paulo: Editora UNESP, 2000.

GUIMARÃES, J. M. M.; ALVES, J. M. Formação de professores na área de educação ambiental: uma análise dos anais da ANPEd (2009-2011). Pesquisa em Educação

Ambiental, v. 7, n. 1, p. 49-67, 2012.

GUIMARÃES, M.. A formação de educadores ambientais. Campinas, S.P.: Papirus, 2004.

GONDIM, S. M. G.. Grupos focais como técnica de investigação qualitativa: desafios metodológicos. Paidéia, 12(24), p. 149-161. 2003. Disponível em:

http://www.scielo.br/pdf/paideia/v12n24/04. Acessado em 19/10/2016.

GUSMÃO, N. M.M.. A Lei n ${ }^{\circ}$ 10.639/2003 e a Formação Docente: desafios e conquistas. In JESUS, R. F.; ARAUJO, M. S.; JUNIOR, H. C.. Dez anos da Lei n 10.639/2003: memórias e perspectivas. Fortaleza: Edições UFC, p. 47- 61. 2013.

HERCULANO, S.. O clamor por justiça ambiental e contra o racismo ambiental. Revista de Gestão Integrada em Saúde do Trabalho e Meio Ambiente (InterfacEHS), v.3, n.1, Artigo 2, jan./ abril 2008. Disponível em:

http://www.professores.uff.br/seleneherculano/images/Oclamor_por_justi\%C3\%A7a_ambi ental_e_contra_racismo_ambiental_9-282-1-PB.pdf. Acesso em 20 de setembro de 2015 .

KASSIADOU, A.M.; SÁNCHEZ, C.P.. O coletivo jovem de meio ambiente e a política governamental de escolas sustentáveis: reflexões sobre possíveis diálogos com a justiça

Rev. Eletrônica Mestr. Educ. Ambient. Rio Grande, v. 36, n. 2, p. 60 - 82, mai./ago. 2019. E-ISSN 1517-1256 
ambiental. Revista de Educação, Ciências e Matemática. v.3 n.3 set/dez 2013 ISSN 2238-2380.

KASSIADOU, A.M.; SÁNCHEZ, C.P.. O coletivo jovem de meio ambiente: uma contribuição à política governamental de escolas sustentáveis dos Ministérios da Educação e do Meio Ambiente. In: VII EPEA - Encontro Pesquisa em Educação Ambiental Rio Claro - SP, 07 a 10 de Julho de 2013.

LAYRARGUES, P.P.. Para onde vai a educação ambiental? O cenário político-ideológico da educação ambiental brasileira e os desafios de uma agenda política crítica contra hegemônica. In: Revista Contemporânea da Educação. vol. 7. n.14. 2012.

LAYRARGUES, P.P. Educação ambiental no Brasil: o que mudou nos vinte anos entre a Rio 92 e a Rio+20. Revista Eletrônica de Jornalismo Científico, LABJOR/SBPC, 2012. Disponível em: http://www.ecodebate.com.br/2012/03/21/educacao-ambiental-no-brasil-oque-mudou-nosvinte-anos-entre-a-rio-92-e-a-rio20-artigo-de-philippe-pomier-layrargues/. Acesso em: 30 de janeiro de 2015.

LAYRARGUES, P.P.; LOUREIRO, C.F.B.. Ecologia política, justiça e educação ambiental crítica: perspectivas de aliança contra-hegemônica. In: Trabalho, educação e Saúde. Rio de Janeiro, v.11.n.1, p.53-71, jan./abr.2013.

LEHER, R.. Educação ambiental como crítica ao desenvolvimento sustentável: desafios dos movimentos e das lutas sociais. In LOUREIRO, C.F.B.; LAMOSA, R. A. C..

Educação ambiental: um balanço crítico da Década da Educação para o Desenvolvimento Sustentável. Rio de Janeiro: Quarter: CNPQ, p. 15 - 138, 2015.

MARTINEZ-ALIER, J.. O ecologismos dos pobres: conflitos ambientais e linguagens de valoração. São Paulo: Contexto, 2011.

MENEZES, A. K.. Escolas sustentáveis e conflitos socioambientais: reflexões sobre o programa governamental das Escolas Sustentáveis sob a ótica da Justiça Ambiental. Dissertação (Mestrado em Educação) - Universidade Federal do Estado do Rio de Janeiro, Rio de Janeiro, 2015.

MIRANDA, C., OLIVEIRA, O. V.. Multiculturalismo crítico, relações raciais e política curricular: a questão do hibridismo na Escola. Revista Brasileira de Educação. Jan /Fev /Mar /Abril, n 25. 2004. disponível em: http://www.scielo.br/pdf/rbedu/n25/n25a06.pdf. Acesso em: 22 de janeiro de 2016.

MIGNOLO, W.. La opción de-colonial: desprendimiento y apertura. Un manifiesto y un caso. Tabula Rasa. Colômbia, $\mathrm{n}^{\circ}$. 8: 243-281, enero-junio 2008. Disponível em: http://www.revistatabularasa.org/numero-8/mignolo1.pdf. acessado em: 02/09/2016. 2008.

PACHECO, T.; FAUSTINO, C.. A iniludível e desumana prevalência do racismo ambiental nos conflitos do mapa. In: Injustiça ambiental e saúde no Brasil: o mapa de

Rev. Eletrônica Mestr. Educ. Ambient. Rio Grande, v. 36, n. 2, p. 60 - 82, mai./ago. 2019. E-ISSN 1517-1256 
conflitos. /organizado por PORTO, M. F., PACHECO, T.; LEROY J. P.. Rio de Janeiro: Editora FIOCRUZ, 2013.

QUEIROZ, M. R.; MIRANDA, C.. Contribuições dos estudos críticos da branquitude para o enfrentamento do racismo na educação superior. REUNIÃO ANUAL DA ASSOCIAÇÃO NACIONAL DE PÓS-GRADUAÇÃO E PESQUISA EM EDUCAÇÃO, 38., 2017, São Luiz, Maranhão. Anais eletrônicos... Maranhão: ANPEd, 2017. Disponível em:

http://anais.anped.org.br/sites/default/files/arquivos/trabalho_38anped_2017_GT21_1015.p df. Acessado em 10 de fevereiro de 2017.

QUIJANO, A.. Colonialidad del Poder, Eurocentrismo y América Latina, In LANDER, E.. La Colonialidad del Saber: Eurocentrismo y ciencias socials. Perspectivas latinoamericanas. Buenos Aires: CLACSO. 2000.

TOZONI-REIS, M. F. C.; TEIXEIRA, L. A.; MAIA, J. S. S.. As publicações acadêmicas e a educação ambiental na escola básica. REUNIÃO ANUAL DA ASSOCIAÇÃO NACIONAL DE PÓS-GRADUAÇÃO E PESQUISA EM EDUCAÇÃO, 34., 2011, Natal, RN. Anais eletrônicos... Natal: ANPEd, 2011. Disponível em:

$<\mathrm{http}$ ///34reuniao.anped.org.br/index.phpoption=com_content\&view=article\&id=135:t rabalhos-gt22-educacao-ambiental\&catid=47:trabalhos\&Itemid=59>. Acesso em: 14 nov. 2011.

TOZONI-REIS, M. F. C.; CAMPOS, L.M.L.. A formação inicial de professores no fortalecimento da educação ambiental escolar: contribuições da pedagogia histórico-crítica. In LOUREIRO, C.F.B.; LAMOSA, R. A. C.. Educação ambiental: um balanço crítico da Década da Educação para o Desenvolvimento Sustentável. Rio de Janeiro: Quarter: CNPQ, p. 105 - 138, 2015.

TRAD, L. A. B.. Grupos focais: conceitos, procedimentos e reflexões baseadas em experiências com o uso da técnica em pesquisas de saúde. Physis, Rio de Janeiro, v. 19, n. 3, p. 777-796, 2009 . Disponível em:

$<$ http://www.scielo.br/scielo.php?script=sci_arttext\&pid=S0103312009000300013\&lng=e n\&nrm=iso >. Acesso em: 23 Jan. 2017.

Submetido em: 19-04-2019.

Publicado em:20-07-2019

Rev. Eletrônica Mestr. Educ. Ambient. Rio Grande, v. 36, n. 2, p. 60 - 82, mai./ago. 2019.

E-ISSN 1517-1256 